Journal of Engineering and Applied Sciences 14 (Special Issue 8): 10298-10304, 2019

ISSN: 1816-949X

(C) Medwell Journals, 2019

\title{
Optimization of Ultrasonic Surface Treatment Condition of CoCrMo (F75) Alloy using Taguchi Method
}

\author{
Zainab Mohammed Lafta, Hayder H.J. Jamal Al-Deen and Ekbal Mohammed Saeed \\ Department of Metallurgical Engineering, College of Materials Engineering, \\ University of Babylon, Babylon, Iraq
}

\begin{abstract}
Co-Cr-Mo alloys represent a very important group of materials used for medical applications due to its strength, corrosion resistance and biocompatibility. In this research, the ultrasonic surface treatment was carried out for F75 alloy prepared by Powder Metallurgy route (PM) using ultrasonic homogenizer under different conditions. Taguchi experimental design concept, L9 $\left(3^{3}\right)$ orthogonal array was utilized in designing the experiments and calculate the Signal to Noise $(\mathrm{S} / \mathrm{N})$ ratio. Analysis of Variance (ANOVA) was carried out to research the significant conditions affecting the hardness, surface roughness, wear rate and corrosion rate in Hank's solution. ANOVA analysis results show that power was the most effective factor for hardness, wear rate and corrosion rate in Hank's solution followed by time and concentration while time was the most effective factor for surface roughness followed by power and concentration. According to Taguchi analysis, the optimum conditions that must be used in ultrasonic surface treatment for CoCrMo alloy are: time ( $90 \mathrm{~min}$ ), power $(80 \%)$, concentration $\left(4 \mathrm{~g} \mathrm{~mL}^{-1}\right)$ to get maximum hardness and minimum wear rate. But, the minimum surface roughness can be achieved with: time $(90 \mathrm{~min})$, power $(80 \%)$, concentration $\left(2 \mathrm{~g} \mathrm{~mL}^{-1}\right)$. While minimum corrosion rate in Hanks solution can get with: time $(90 \mathrm{~min})$, power $(60 \%)$, concentration $\left(6 \mathrm{~g} \mathrm{~mL}^{-1}\right)$. In addition, mathematical models were developed successfully for prediction of properties with acceptable error percentage.
\end{abstract}

Key words: CoCrMo alloy, ultrasonic surface treatment, Taguchi method, powder metallurgy, concentration, mathematical models

\section{INTRODUCTION}

Biomaterial used for implants can be metals, polymers, ceramics and composites. Metallic implants attracted high attention compared to other biomaterials as a result of their high impact strength, high ductility, high wear resistance and toughness (Moravej and Mantovani, 2011). Generally, there are three types of metal which can be used as implants: cobalt-chromium alloys, austenitic stainless steels and $\mathrm{Ti}$ and its alloys that used in dental and medical applications for the making of biodevices for extended life in the human body which satisfy the requirements of orthopedic implants applications (Hermawan et al., 2011). The head most and prerequisite for the choice of the biomaterial is its biocompatibility by the human body which means it should not cause any adverse effects. Secondly, it should have sufficient mechanical strength to endure the forces to which they are subjected, so that, they do not undergo fracture, bioimplant should possess very high wear and corrosion resistance in varying loading conditions and highly corrosive body environment, apart from fatigue strength and fracture toughness (Manivasagam et al., 2010). The Co-28Cr-6Mo alloy (ASTM F75) possess high wear resistance and superior mechanical properties than titanium alloys in the human body these alloys have higher corrosion resistance than the stainless steel $316 \mathrm{~L}$. The corrosion reactions with the body fluids and biological tissues are the main factors for degrading the implanted materials. Generally, the current materials used for implant found to be unsuccessful within a duration of about 12-15 years (Niinomi, 2002). One of the ways to improve the biomaterial properties is surface modifications.

Ultrasonic Impact Treatment (UIT) is a progressive and very promising method in modem technology which brings about severe plastic deformation and allows fast modification of composition and structure of the surface layers (Vasylyev et al., 2016). The UIT may be considered as one of the methods that lead to high surface deformation by applied ultrasonic vibrations this technique similar to work hardening (Galtier and Statnikov, 2004).

\section{MATERIALS AND METHODS}

Experimental procedure: The powders of cobalt, chromium, molybdenum, nickel, manganese, silicon, iron

Corresponding Author: Zainab Mohammed Lafta, Department of Metallurgical Engineering, College of Materials Engineering, University of Babylon, Babylon, Iraq 
J. Eng. Applied Sci., 14 (Special Issue 8): 10298-10304, 2019

Table 1: Purity and average particle size of the used powders

\begin{tabular}{lcc}
\hline Powder & Purity & Average particles size $(\mu \mathrm{m})$ \\
\hline Cobalt & 99.97 & 5.337 \\
Chromium & 99.85 & 39.580 \\
Molybdenum & 99.64 & 10.670 \\
Nickel & 99.86 & 29.250 \\
Manganese & 99.87 & 185.600 \\
Silicon & 99.79 & 7.269 \\
Iron & 99.83 & 21.880 \\
\hline
\end{tabular}

and carbon were supplied from HWNANO company in China. X-ray fluorescence analysis using an analyzer of type (Ds-2000) and particle size analysis using laser particle size analyzer of type: were carried out to the used powders. The results are demonstrated in Table 1.

Samples preparation: Cylindrical samples with $13 \mathrm{~mm}$ in diameter and $8 \mathrm{~mm}$ in height were prepared. The chemical composition of F75 alloy is $60.4 \mathrm{Co}+28$ $\mathrm{Cr}+6 \mathrm{Mo}+2 \mathrm{Ni}+1 \mathrm{Si}+1 \mathrm{Mn}+0.75 \mathrm{Fe}+0.35 \mathrm{C}$ (in wt.\%) according to ASTM F75 (ASTM., 2012). A wet mixing was used with $2 \mathrm{wt} . \%$ of acetone. A mixing process for $5 \mathrm{~h}$ was achieved by a ball mill of type (STGQM-15/-2). Uniaxial compacting via. double action steel die was carried out on electro hydraulic compacting machine of type (CT340-CT440, USA), lubricant was used for the inside walls of the steel die. A compacting pressure of $800 \mathrm{MPa}$ was used to prepare all samples, this pressure was determined experimentally based on a highest green density. The sintering process of the green compacts was achieved via. vacuum high temperature tube furnace type (GSL 1600X/MTI) the sintering process was performed in an argon atmosphere. The sintering program with heating rate of $10^{\circ} \mathrm{C} \mathrm{min}^{-1}$ was done by two steps, the first step was at $500^{\circ} \mathrm{C}$ for $120 \mathrm{~min}$ and the second step was at $950^{\circ} \mathrm{C}$ for $300 \mathrm{~min}$, the samples were left inside the furnace to cool down.

Microstructure analysis: Optical microscope analysis, Scanning Electron Microscopy (SEM) and X-Ray Diffraction (XRD) analysis were performed to the prepared F75 alloy to insure the success of the sintering by identifying the created phases. Optical microscope analysis and SEM was carried out to sintered F75 alloy after polishing and etching using optical microscope of type (MMM-800RF) and SEM type (VEGA3 LM/TESCAN). X-ray diffraction analysis was carried out using XRD analyzer of type (XRD6000) with testing conditions of (Target: $\mathrm{Cu}$, voltage and current are 40 $\mathrm{KV}$ and $30 \mathrm{~mA}$, respectively scanning speed of $5 \mathrm{~min}^{-1}$ and scanning range of 5-120).

Ultrasonic surface treatment: Ultrasonic surface treatment used to modify and improve the surface characteristics without effect on the bulk properties by using a sullary composed from distilled water and nano
Table 2: Control factors and their levels

\begin{tabular}{lcllll}
\hline & & \multicolumn{4}{c}{ Levels } \\
Parameters & Designation & Units & 1 & 2 & 3 \\
\hline Time & $\mathrm{t}$ & Min & 30 & 60 & 90 \\
Power of 1200 & $\mathrm{P}$ & Watt & 40 & 60 & 80 \\
Concentration & $\mathrm{C}$ & $\mathrm{gmL}^{-1}$ & 2 & 4 & 6 \\
\hline
\end{tabular}

particles of $\mathrm{ZiO}_{2}$. The samples were ultrasonic surface treated according to a program designed via. Taguchi method. L9 orthogonal array was used in this study to identify the effect of ultrasonic surface treatment parameters (time, power, concentration) on the Hardness $(\mathrm{Hv})$, surface Roughness (Ra), Wear Rate (W.R) and Corrosion Rate in Hank's solution (CR). Table 2 demonstrates the controlled factors, designation and levels. All experiments were conducted inultrasonic homogenizer cell. The samples were treated by ultrasonic cell crusher type (1200 W-MTI). The total power of the ultrasonic homogenizer is $1200 \mathrm{~W}$ at constant temperature of $50^{\circ} \mathrm{C}$.

After each ultrasonic surface treatment the hardnesswere recorded using vickers micro-hardness device of type (TH 717) with a load of $200 \mathrm{~g}$ for $10 \mathrm{sec}$. The hardness was recorded as an average of five readings for each sample. The surface roughness of the samples has been measured by using surface roughness tester of type (TR210) an average of five measurements was considered in this test.

The wear rate was calculated experimentally by calculating the weight loss from the sample per the experimental density according to Eq. 1. The dry sliding wear was studied by using the pin on disk concept using $200 \mathrm{rpm}$ and constant radius $8 \mathrm{~mm}$ with different sliding distance and the load $20 \mathrm{~N}$. Before wear test the samples were dried at $50^{\circ} \mathrm{C}$ for $2 \mathrm{~h}$ and cooling in the furnace then the samples were weighted using $(0.0001)$ accuracy electric balance. The sample was weighted after a period of time $5,10,15,20$ and $25 \mathrm{~min}$. This test was carried out using wear tester device type (MT-4003). The test method had been covered according to ASTM G 99 (ASTM., 2004):

$$
\text { Wear rate }=\frac{\text { weigth } \operatorname{loss}(\mathrm{g})}{\rho\left(\frac{\mathrm{g}}{\mathrm{cm}^{3}}\right)}
$$

Where:

Weight: Quantity loss after 5, 10, 15, 20 and $25 \mathrm{~min}$

loss

$\rho \quad:$ The experimental density

The corrosion rate in Hank's solution was investigated by tafel extrapolation type (WENDKING M lap). Three electrodes were used for polarization test: the counter electrode was $\mathrm{Pt}$ electrode and the reference electrode was the Saturated Calomel (SCE) while the 
sample was the working electrode according to ASTM. The test was conducted by stepping the potential using a scanning rate $0.4 \mathrm{mV} \mathrm{sec}^{-1}$ from the initial potential of $350 \mathrm{mV}$ below the open circuit potential and the scan continued up to $350 \mathrm{mV}$ above the open circuit potential. Corrosion rate measurement is obtained by applying Eq. 2 (ASTM G102-89, 1999):

$$
\text { Corrosion rate }=\frac{0.13 \mathrm{Icorr}(\mathrm{Ew})}{\rho}
$$

Where:

EW : Equivalent Weight (g/eq.)

$\rho$ : Density $\left(\mathrm{g} \mathrm{cm}^{-3}\right)$

0.13 : Metric and time conversion factor

Icorr. : Current density $\left(\mu \mathrm{A} \mathrm{cm}^{-2}\right)$

mpy : Corrosion rate (mils per year)

\section{RESULTS AND DISCUSSION}

Microstructure analysis: Figure 1 and 2 illustrates the microstructures of sintered $\mathrm{F} 75$ which obtain from optical microscope analysis and scanning electron microscopy, respectively. Figure 3 demonstrates the XRD analysis for F75 alloy.

The microstructure of the sintered alloy insures the formation of a multiphase structure in which the two phases $\left(\mathrm{CoCr}\right.$ and $\left.\mathrm{Co}_{2} \mathrm{Mo}_{3}\right)$ are embedded in uniformly matrix (CoCrMo-F.C.C). As well as there are many pores in different size can be seen on the surface and it is a natural manner because the samples are prepared by powder metallurgy technique.

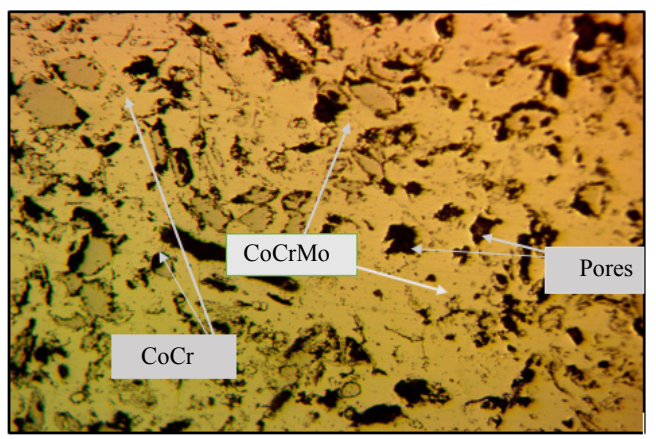

Fig. 1: Microstructure of prepared F75 alloyat $200 \mathrm{X}$ magnification after sintering and etching
The diffraction patterns in XRD analysis show that all $\mathrm{Co}, \mathrm{Cr}$ and $\mathrm{Mo}$ transformed to $\mathrm{CoCrMo}, \mathrm{CoCr}$ and $\mathrm{CO}_{2} \mathrm{MO}_{3}$ phases. This means that the sintering process period $(5 \mathrm{~h})$ was enough to complete the phase transformation process where phase transformation is diffusion process and needs a high temperature to occur. The absence of free elements is necessary in this alloy which used as biomaterials due to it toxicity effect into body.

Ultrasonic surface treatment result: Table 3 shows all the experimental results of the responses: Hardness $(\mathrm{Hv})$, surface Roughness (Ra), Wear Rate (WR)and corrosion rate in Hank's solution (CR). The hardness was obtained in the range of $175-275 \mathrm{Hv}$, surface roughness, wear rate

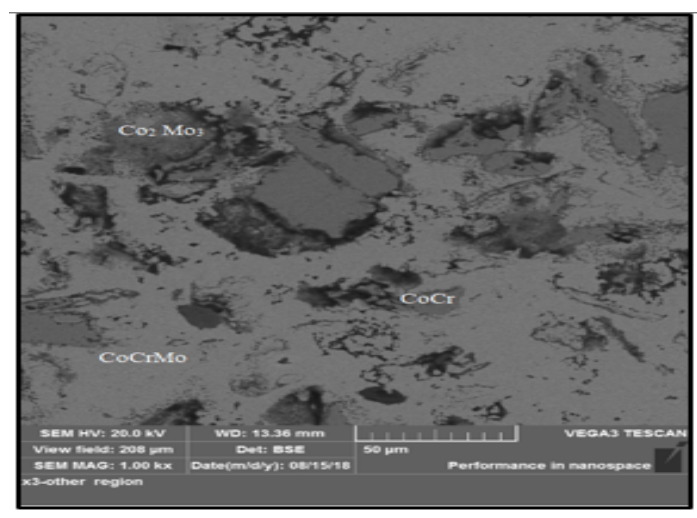

Fig. 2: SEM images of prepared F75 alloy after sintering

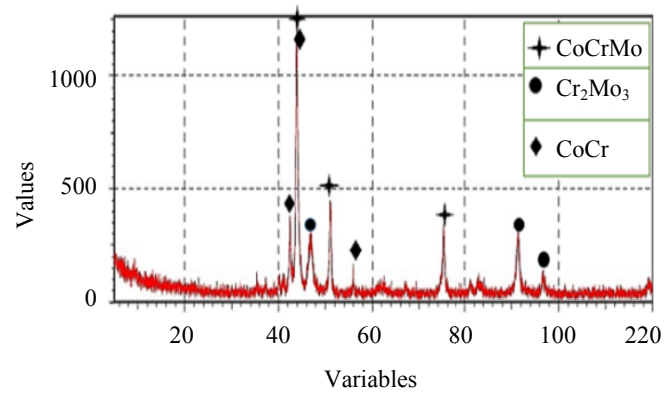

Fig. 3: XRD pattern of prepared F75 alloy after sintering

Table 3: Experimental result for the responses

\begin{tabular}{|c|c|c|c|c|c|c|c|}
\hline Exp. No. & $\mathrm{t}(\mathrm{min})$ & $\mathrm{p}(\%)$ & $\mathrm{C}\left(\mathrm{gmL}^{-1}\right)$ & $\mathrm{Hv}(\mathrm{HV})$ & $\mathrm{Ra}(\mu \mathrm{m})$ & WR $\left(\mathrm{cm}^{3}\right)$ & CR1 (mpy) \\
\hline 1 & 30 & 40 & 2 & 175 & 0.484 & 0.00134 & 1.13430 \\
\hline 2 & 30 & 60 & 4 & 202 & 0.432 & 0.00123 & 1.02009 \\
\hline 3 & 30 & 80 & 6 & 232 & 0.306 & 0.00113 & 1.10460 \\
\hline 4 & 60 & 40 & 4 & 183 & 0.365 & 0.00129 & 1.03460 \\
\hline 5 & 60 & 60 & 6 & 197 & 0.261 & 0.00126 & 0.75810 \\
\hline 6 & 60 & 80 & 2 & 242 & 0.220 & 0.00098 & 1.59120 \\
\hline 7 & 90 & 40 & 6 & 210 & 0.299 & 0.00114 & 0.83260 \\
\hline 8 & 90 & 60 & 2 & 224 & 0.126 & 0.00121 & 0.74730 \\
\hline 9 & 90 & 80 & 4 & 275 & 0.108 & 0.00086 & 1.03010 \\
\hline
\end{tabular}



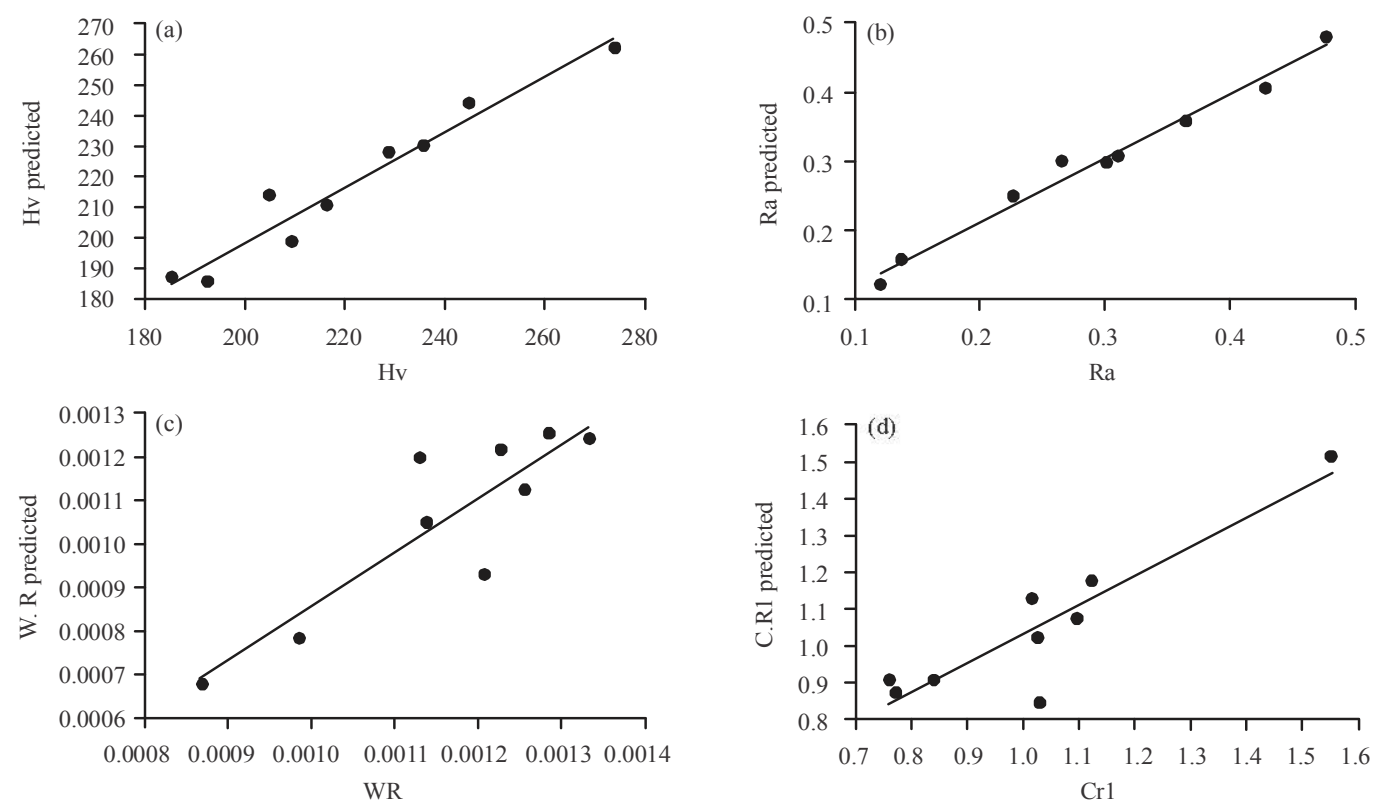

Fig. 4: Scatterplot of the experimental and predicted values for; (a) Hardness, (b) Surface roughness, (c) Wear rate and (d) Corrosion rate in Hank's solution; scatterplot of Hv predicted vs. Hv; scatterplot of Ra predicted vs. Ra; scatterplot of WR predicted vs WR; scatterplot of CR1 predicted vs. CR1

and corrosion rate in Hank's solution were obtained in the range of $0.484-0.108 \mu \mathrm{m}, 0.00134-0.00086 \mathrm{~cm}^{3}$ and $1.1343-0.7473 \mathrm{mpy}$, respectively.

The relationship between the inputs $(\mathrm{t}, \mathrm{p}$ and $\mathrm{C})$ and outputs (Hv, Ra, WR and $\mathrm{CR}$ ) was modelled by regression equations using Minitab (Version 18). These developed models can be used to predict the hardness, surface roughness, wear rate and corrosion rate in Hank's solution for any collection of the time, power and concentration values within the range of the conducted experiments. The models and its determination coefficients obtained for different cutting phenomena are presented in (3-6), respectively to $(\mathrm{Hv}, \mathrm{Ra}, \mathrm{WR}$ and CR):

$$
\begin{aligned}
& \mathrm{Hv}=148.5+0.51 \mathrm{t}+1.55 \mathrm{P}-34.9 \mathrm{C}-0.0133 \\
& \mathrm{t} * \mathrm{P}+0.260 \mathrm{t} * \mathrm{C}+0.286 \mathrm{P} * \mathrm{C}
\end{aligned}
$$

$$
\mathrm{R}^{2}=94.82 \%
$$

$\mathrm{Ra}=0.755-0.00567 \mathrm{t}-0.00143$ P-0 0164

$\mathrm{C}-0.000012 \mathrm{t}^{*} \mathrm{P}+0.000595 \mathrm{t}^{*} \mathrm{C}-0.000304 \mathrm{P}^{*} \mathrm{C}$

$$
\mathrm{R}^{2}=98.51 \%
$$

$\mathrm{W} \cdot \mathrm{R}=0.001466+0.000002 \mathrm{t}-0.000011 \mathrm{P}+0.000158$ $\mathrm{C}+0.000000 \mathrm{t} * \mathrm{P}-0.000002 \mathrm{t}{ }^{*} \mathrm{C}-0.000000 \mathrm{P} * \mathrm{C}$

$$
\mathrm{R}^{2}=91.74 \%
$$

$$
\begin{aligned}
& C R=0.71-0.0068 \mathrm{t}+0.0305 \mathrm{P}-0.198 \\
& \mathrm{C}-0.000200 \mathrm{t}^{*} \mathrm{P}+0.00350 \mathrm{t}^{*} \mathrm{C}-0.00179 \mathrm{P}^{*} \mathrm{C}
\end{aligned}
$$

$$
\mathrm{R}^{2}=87.08 \%
$$

The above models can be used to predict hardness, surface roughness, wear rate and corrosion rate in Hank's solution at the particular design point's. The differences between measured results and predicted results based on these models are illustrated in Fig. 4. These figures indicate that the developed models are capable to representing the system under the given experimental domain.

The most essential criterion in the Taguchi method for analysing experimental data is signal/noise ratio. In this study to obtain the optimal UST conditions, the larger is the better characteristic has been chosen for Hardness (Hv) while the smaller is better characteristic has been chosen for Corrosion Rate in Hank's solution (C.R), Wear Rate (W.R) and surface Roughness (Ra). Signal-to-noise ratio were calculated for each experimental run using Minitab 18 Software program based on the experimental results. From Taguchi analysis results, the most effective ultrasonic treatment parameters on each property ( $\mathrm{Hv}, \mathrm{Ra}$, W.R and C.R) and optimum UST conditions can be determined. The response vales for signal-to-noise ratio of Hv, Ra, W.R and C.R are shown in Table 4. From this Table 4, the most significant factors that control each 

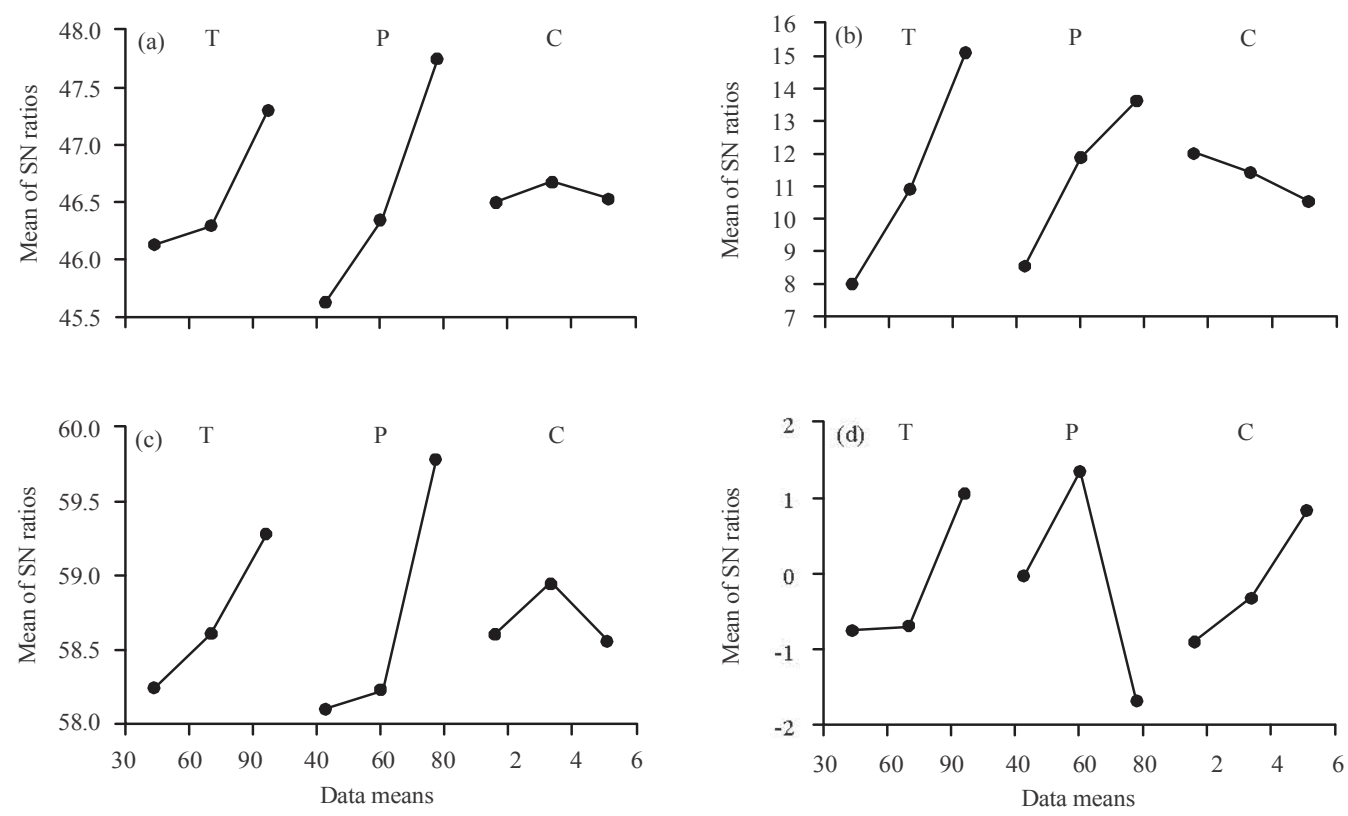

Fig. 5: Main effect plot for $\mathrm{S} / \mathrm{N}$ ratio of (a) Hardness, (b) Surface roughness, (c) Wear rate and (d) Corrosion rate in Hank's solution; main effects plot for SN ratios data means

Table 4: Response values for signal-to-noise ratio

\begin{tabular}{|c|c|c|c|}
\hline Level & $\mathrm{T}$ & $\mathrm{P}$ & $\mathrm{C}$ \\
\hline \multicolumn{4}{|c|}{ Hardness (Hv) } \\
\hline \multicolumn{4}{|c|}{ Response values for signal to noise ratios: larger is better } \\
\hline 1 & 46.09 & 45.52 & 46.51 \\
\hline 2 & 46.27 & 46.33 & 46.71 \\
\hline 3 & 47.41 & 47.92 & 46.55 \\
\hline Delta & 1.32 & 2.41 & 0.20 \\
\hline Rank & 2 & 1 & 3 \\
\hline \multicolumn{4}{|c|}{ Surface Roughness (Ra) } \\
\hline \multicolumn{4}{|c|}{ Response values for signal to noise ratios: smaller is better } \\
\hline 1 & 7.960 & 8.515 & 12.482 \\
\hline 2 & 11.191 & 12.317 & 11.792 \\
\hline 3 & 15.937 & 14.256 & 10.813 \\
\hline Delta & 7.997 & 4.742 & 1.669 \\
\hline Rank & 1 & 2 & 3 \\
\hline \multicolumn{4}{|c|}{ Wear Rate (WR) } \\
\hline \multicolumn{4}{|c|}{ Response values for signal to noise ratios: smaller is better } \\
\hline 1 & 58.20 & 58.04 & 58.66 \\
\hline 2 & 58.65 & 58.18 & 59.10 \\
\hline 3 & 59.51 & 60.14 & 58.60 \\
\hline Delta & 1.31 & 2.11 & 0.50 \\
\hline Rank & 2 & 1 & 3 \\
\hline \multicolumn{4}{|c|}{ Corrosion rate in Hank's solution } \\
\hline \multicolumn{4}{|c|}{ Response values for signal to noise ratios: smaller is better } \\
\hline 1 & -0.7104 & 0.06709 & -0.8663 \\
\hline 2 & -0.6414 & 1.58760 & -0.2419 \\
\hline 3 & 1.2879 & -1.7187 & 1.04421 \\
\hline Delta & 1.9984 & 3.30633 & 1.91053 \\
\hline Rank & 2 & 1 & 3 \\
\hline
\end{tabular}

property (Hv, Ra, W.R and CR) can be noticed. For example, it can be noticed that for hardness, the highest variation in $\mathrm{S} / \mathrm{N}$ ratio is for time. $\mathrm{S} / \mathrm{N}$ values for ranges from 46.09-47.41. This clearly indicates that this factor plays very important role in this process, so, it has the first rank in affecting the hardness. By the same method, the UST parameters were ranked for each property. Figure 5 show the results of Taguchi design analysis (main effect plots for S/N ratio) for Hv, C.R1, C.R2, WR and Ra. From this Fig. 5, the optimum ultrasonic conditions that give maximum hardness, minimum surface roughness, minimum wear rate and minimum corrosion rate in in Hank's solution can be determined. So, the factors giving the maximum hardness were specified as time ( $\mathrm{t} 3$, $\mathrm{S} / \mathrm{N}=47.41)$, Power $(\mathrm{P} 3, \mathrm{~S} / \mathrm{N}=47.92)$ and Concentration $(\mathrm{C} 2, \mathrm{~S} / \mathrm{N}=46.71)$. In another way, a good hardness value was obtained with the time $90 \mathrm{~min}$ at the power $80 \%$ and at the concentration $4 \mathrm{~g} \mathrm{~mL}^{-1}$.

Similarly, the factors giving the minimum surface roughness were specified as time $(\mathrm{t} 3, \mathrm{~S} / \mathrm{N}=15.937)$, Power $(\mathrm{P} 3, \mathrm{~S} / \mathrm{N}=14.256)$ and $(\mathrm{Cl}, \mathrm{S} / \mathrm{N}=12.482)$. In another way, the minimum surface roughness was obtained at the time 90 at the power 80 and at the concentration $2 \mathrm{~g} \mathrm{~mL}^{-1}$.

The factors giving the minimum wear rate were specified as time ( $\mathrm{t} 3, \mathrm{~S} / \mathrm{N}=59.51)$, Power ( $\mathrm{P} 3$, $\mathrm{S} / \mathrm{N}=60.14)$ and $(\mathrm{C} 2, \mathrm{~S} / \mathrm{N}=59.10)$. In another way, the minimum wear rate was obtained at the time 90 at the power 80 and at the concentration $4 \mathrm{~g} \mathrm{~mL}^{-1}$.

The factors giving the minimum corrosion rate in Hanks solution were specified as time $(\mathrm{t} 3, \mathrm{~S} / \mathrm{N}=1.2879)$, Pzower $(\mathrm{P} 2, \mathrm{~S} / \mathrm{N}=1.58760)$ and $(\mathrm{C} 3, \mathrm{~S} / \mathrm{N}=1.04421)$. In another way, the minimum corrosion rate in Hanks solution was obtained at the time 90 at the power 60 and at the concentration $6 \mathrm{~g} \mathrm{~mL}^{-1}$.

By ANOVA analysis results we can determine the contribution percentage of ultrasonic parameters in controlling of each property ( $\mathrm{Hv}, \mathrm{Ra}, \mathrm{W} . \mathrm{R}$ and C.R). The results of ANOVA analysis for these properties are listed in Table 5-8. 
Table 5: ANOVA results for hardness

\begin{tabular}{|c|c|c|c|c|c|}
\hline Sources & $\mathrm{df}$ & Adj SS & Adj MS & F-value & p-value \\
\hline \multicolumn{6}{|c|}{ Hardness versus time } \\
\hline $\mathrm{T}$ & 2 & 1971 & 985.4 & 1.01 & 0.419 \\
\hline Error & 6 & 5867 & 977.9 & & \\
\hline Total & 8 & 7838 & & & \\
\hline \multicolumn{6}{|c|}{ Hardness versus power } \\
\hline $\mathrm{P}$ & 2 & 5740 & 2870.1 & 8.21 & 0.019 \\
\hline Error & 6 & 2098 & 349.7 & & \\
\hline Total & 8 & 7838 & & & \\
\hline \multicolumn{6}{|c|}{ Hardness versus concentration } \\
\hline $\mathrm{C}$ & 2 & 89.56 & 44.78 & 0.03 & 0.966 \\
\hline Error & 6 & 7748.67 & 129144 & & \\
\hline Total & 8 & 7838.22 & & & \\
\hline
\end{tabular}

Table 6: ANOVA results for surface roughness

\begin{tabular}{lccccc}
\hline Sources & df & Adj SS & Adj MS & F-value & p-value \\
\hline \multicolumn{5}{l}{ Surface roughness versus time } \\
$\mathrm{T}$ & 2 & 0.07934 & 0.039670 & 4.74 & 0.058 \\
Error & 6 & 0.05017 & 0.008362 & & \\
Total & 8 & 0.12951 & & & \\
\multicolumn{5}{l}{ Surface roughness versus power } \\
$\mathrm{P}$ & 2 & 0.04518 & 0.02259 & 1.61 & 0.276 \\
Error & 6 & 0.08433 & 0.01405 & & \\
Total & 8 & 0.12951 & & & \\
Surface roughness versus concentration & & \\
$\mathrm{C}$ & 2 & 0.000938 & 0.000469 & 0.02 & 0.978 \\
Error & 6 & 0.128576 & 0.021429 & & \\
Total & 8 & 0.129514 & & & \\
\hline
\end{tabular}

Table 7: ANOVA results for wear rate

\begin{tabular}{lccccc}
\hline Sources & df & Adj SS & Adj MS & F-value & p-value \\
\hline \multicolumn{5}{l}{ Wear rate versus time } \\
T & 2 & 0.0000004 & 0.000002 & 0.83 & 0.481 \\
Error & 6 & 0.0000015 & 0.000002 & & \\
Total & 8 & 0.0000190 & & & \\
\multicolumn{7}{l}{ Wear rate versus power } \\
$\mathrm{P}$ & 2 & 0.0000130 & 0.000007 & 6.59 & 0.031 \\
Error & 6 & 0.0000060 & 0.000001 & & \\
Total & 8 & 0.0000019 & & & \\
Wear rate versus concentration & & & \\
$\mathrm{C}$ & 2 & 0.0000002 & 0.000001 & 0.08 & 0.923 \\
Error & 6 & 0.0000017 & 0.000003 & & \\
Total & 8 & 0.0000019 & & & \\
\hline
\end{tabular}

Table 8: ANOVA results for corrosion rate in hanks solution

\begin{tabular}{|c|c|c|c|c|c|}
\hline Sources & $\mathrm{df}$ & Adj SS & Adj MS & F-value & $\mathrm{p}$-value \\
\hline \multicolumn{6}{|c|}{ Corrosion rate in Hanks solution versus time } \\
\hline $\mathrm{T}$ & 2 & 0.1151 & 0.05754 & \multirow[t]{3}{*}{0.84} & \multirow[t]{3}{*}{0.475} \\
\hline Error & 6 & 0.4092 & \multirow[t]{2}{*}{0.06820} & & \\
\hline Total & 8 & 0.5243 & & & \\
\hline \multicolumn{6}{|c|}{ Corrosion rate in Hanks solution versus power } \\
\hline $\mathrm{P}$ & 2 & 0.2436 & 0.12180 & \multirow[t]{3}{*}{2.60} & \multirow[t]{3}{*}{0.153} \\
\hline Error & 6 & 0.2807 & 0.04678 & & \\
\hline Total & 8 & 0.5243 & & & \\
\hline \multicolumn{6}{|c|}{ Corrosion rate in Hanks solution versus concentration } \\
\hline $\mathrm{C}$ & 2 & 0.1008 & 0.50380 & 0.71 & \multirow[t]{3}{*}{0.527} \\
\hline Error & 6 & 0.4235 & 0.07059 & & \\
\hline Total & 8 & 0.5243 & & & \\
\hline
\end{tabular}

The contribution percentage can be determined by dividing the SS of each parameter on the total the SS. The most significant machining parameters that affect each property and their contribution percentage are listed in Table 9.
Table 9: Contribution percentage of ultrasonic conditions in each property

\begin{tabular}{lccc}
\hline & \multicolumn{3}{c}{ Contribution percentage } \\
& - Time & Power & Concentration \\
\hline Responses & 25 & 73 & 1.15 \\
Surdness & 61 & 35 & 0.73 \\
Wear rate & 21 & 68 & 10.50 \\
Corrosion rate in Hanks solution & 22 & 46 & 19.00 \\
\hline
\end{tabular}

The analysis shows a small effect of concentration on the hardness compared with the time and power. The analysis of the effect of ultrasonic parameter on hardness shows that the power has the largest effect on the hardness. The hardness increases significantly with increasing the power. According to the analysis the hardness also increases with increase the time of the treatment.

Also the analysis shows improvement in surface quality (decrease in surface roughness) with the increase of power. At high power, surface roughness was reduced. The analysis shows that the time has extremely large effect on surface roughness compared with concentration and the power as a result to high energy and vibration induce as time increase.

As well as the analysis shows improvement in surface quality (decrease in surface roughness) with the increase of power. At high power, surface roughness was reduced. The analysis shows that the time has extremely large effect on surface roughness compared with concentration and the power as a result to high energy and vibration induce as time increase.

In addition, the analysis shows a small effect of concentration on the corrosion rate in Hanks solution compared with the time and power. The analysis of the effect of ultrasonic parameter on the corrosion rate in Hanks solution shows that the power has the largest effect. The corrosion resistance increases significantly with increasing the power. But at the maximum value of power the corrosion resistance decrease due to high compressive stresses induce on the surface. According to the analysis the corrosion resistance also increases with increase the time of the treatment due to the increases in the thickening of the passive layer which formed spontaneously.

\section{CONCLUSION}

The sintering at $950^{\circ} \mathrm{C}$ for $5 \mathrm{~h}$ under an argon atmosphere is enough to complete the phase transformation process of $\mathrm{Co}, \mathrm{Cr}$, Mo to alloy structure that consist of three phases: $\mathrm{CoCrMo}, \mathrm{CoCr}$ and $\mathrm{Co}_{2} \mathrm{Mo}_{3}$.

The power has a greater influence on the hardness $(73 \%)$ followed by time $(25 \%)$ while a very slight effect by concentration can be notice $(1.15 \%)$. Surface 
roughness mainly affected by time follow by power with contribution of 61 and $35 \%$, respectively. The power has a larger effect on the wear rate (68\%) followed by time (21\%) and concentration (10.5). The corrosion rate in Hanks solutionmainly affected by power (46\%) follow bt time (22\%), concentration (19\%).

The optimum ultrasonic surface treatment conditions that must be used in treated CoCrMo alloy according to Taguchi analysis results are: time (90 min), power (80\%) and concentration $\left(4 \mathrm{~g} \mathrm{~mL}^{-1}\right)$ to get maximum hardness and minimum wear rate. But the minimum surface roughness can be achieved with: time $(90 \mathrm{~min})$, power $(80 \%)$ and concentration $\left(2 \mathrm{~g} \mathrm{~mL}^{-1}\right)$ while minimum corrosion rate in Hanks solution and can get with: time (90 min), power $(60 \%)$, concentration $\left(6 \mathrm{~g} \mathrm{ML}^{-1}\right)$. The developed model presented predicted results with permissible error range to the experimental results.

\section{ACKNOWLEDGEMENTS}

The researchers wish to acknowledge the entire staff of Materials Engineering College/University of Babylon/Iraq for their extended help during experimental activities.

\section{REFERENCES}

ASTM G102-89, 1999. Standard Practice for Calculation of Corrosion Rates and Related Information from Electrochemical Measurements. ASTMInternational, West Conshohocken, Pennsylvania, USA.,.
ASTM., 2004. G99-04a, standard test method for wear testing with a pin-on-disk apparatus. ASTM International, West Conshohocken, Pennsylvania. https://www .astm. org/DATABASE.CART/HISTO RICAL/G99-04A.htm

ASTM., 2012. Standard specification for cobalt-28 chromium- 6 molybdenum alloy castings and casting alloy for surgical implants (UNS R30075). ASTM International, West Conshohocken, Pennsylvania, USA.

Galtier, A. and E.S. Statnikov, 2004. The influence of ultrasonic impact treatment on fatigue behaviour of welded joints in high-strength steel. Weld. World, 48: 61-66.

Hermawan, H., D. Ramdan and J.R.P. Djuansjah, 2011. Metals for biomedical applications. Master Thesis, Faculty of Biomedical Engineering and Health Science, University Teknologi Malaysia, Johor Bahru, Malaysia.

Manivasagam, G., D. Dhinasekaran and A. Rajamanickam, 2010. Biomedical implants: Corrosion and its prevention-a review. Recent Pat. Corros. Sci., 2: 40-45.

Moravej, M. and D. Mantovani, 2011. Biodegradable metals for cardiovascular stent application: Interests and new opportunities. Int. J. Mol. Sci., 12: 4250-4270.

Niinomi, M., 2002. Recent metallic materials for biomedical applications. Metall. Mater. Trans. A., 33: 477-486.

Vasylyev, M.A., S.P. Chenakin and L.F. Yatsenko, 2016. Ultrasonic impact treatment induced oxidation of Ti6Al4V alloy. Acta Mater., 103: 761-774. 